\title{
Multinational Dividend Policies: A Systematic Literature Review to Future
}

\author{
Submitted 11/12/20, $1^{\text {st }}$ revision 20/01/21, $2^{\text {nd }}$ revision 18/02/21, accepted 20/03/21
}

\author{
Eduardo C. Oliveira ${ }^{1}$, Michele N. Jucá ${ }^{2}$
}

\begin{abstract}
:
Purpose: To identify knowledge gaps about multinational companies' dividend distribution policy.

Design/Approach/Methodology: A bibliometric analysis and systematic review on the theme is carried out, considering the period between January 1972 and August 2020. The database used is the Web of Science.

Findings: Among the knowledge gaps, an opportunity stands out for comparative analysis of the dividend distribution policy between multinational and domestic companies - or subsidiaries - especially in emerging markets. Other gaps identified are the impact of share buybacks, profit repatriation, mergers and acquisitions, foreign exchange, taxes, credit supply, and other characteristics of each country about these companies' payout ratio.

Practical Implication: This study contributes to the bibliometric analysis of the most recent studies about dividend distribution policy between multinational and domestic companies. Also, it points out knowledge gaps on the topic, presenting suggestions for evolution to other researchers.

Originality/Value: Absence of studies that combine quantitative method - bibliometric analysis - and qualitative method - literature systematic review. Additionally, for the bibliometric analysis, the laws of Zifp, Bradford, and Lotka are applied.
\end{abstract}

Keywords: Multinational companies, domestic companies, dividend policy, bibliometric analysis, systematic review.

JEL codes: $F 23$, G35.

Paper Type: Literature review study.

\footnotetext{
${ }^{1}$ Mackenzie Presbyterian University, Center for Social and Applied Sciences, São Paulo, Brazil, https://orcid.org/0000-0001-9409-9520, eduardocezar.oliveira@bol.com.br; ${ }_{2}^{2}$ Mackenzie Presbyterian University, Center for Social and Applied Sciences, São Paulo, Brazil, https://orcid.org/0000-0002-8610-6193, michele.juca@mackenzie.com.br;
} 


\section{Introduction}

Dividend distribution policy is a topic that has been discussed in the academy for a long time, especially about the identification of its determinants. Among the theories on dividend distribution policy, the dividend irrelevance (Miller and Modigliani 1961) and a bird in the hand (Lintner 1962; Gordon 1959, 1963) stand out. For Miller and Modigliani (MM) (1961), in a perfect market, the company's value is not affected by the dividend distribution but by its ability to generate future cash flows.

In opposition to MM, Lintner (1962) and Gordon (1959, 1963) state that dividends are relevant. Thus, investors prefer to receive dividends as soon as possible, reducing the uncertainty of the return on their investment, which ends up by raising the share price. In turn, Spence (1973) opposes the existence of a perfect market. According to him, companies end up signaling changes in their future cash flows via changes in their dividend distribution policy - which are communicated in the publication of relevant facts.

Since these authors' seminal works, empirical studies seek to identify the determinants of dividend distribution policies, using these referred theories as the basis for their hypotheses. Among the main determinants analyzed are the country's culture, political crises, mergers and acquisitions, taxes, and capital repatriation (Shao et al., 2010, Huang et al., 2015, Glendening et al., 2016, Harju and Kari, 2017, Akhtar, 2018a).

However, there is a scarcity of studies dealing with the distinction between multinational (MNC) and domestic (DC) companies relating to the dividend distribution policy. Expanding a company's business overseas may increase its total profit. However, having assets outside the country of origin increases the business's political risk. Also, the difference in tax rates may affect dividend repatriation. Thus, this study seeks to answer the following question: What is the impact of companies having assets and revenues outside their country of origin on their dividend distribution policy?

To answer this question, bibliometric analysis and systematic review are carried out on the topic, considering the period between January 1972 and August 2020. According to Tranfield (2003), systematic reviews differ from traditional narratives by adopting a replicable, scientific, and transparent process. It aims at minimizing bias through exhaustive searches in the literature of published articles, besides providing an audit trail of decisions, procedures by reviewers, and conclusions. Thus, the proposed challenge is to identify relevant studies, knowledge gaps, and directions for future studies about the question-problem.

For such, the following steps are necessary: a) to identify the most relevant articles analyzing the companies' dividend distribution policy - with a special focus on the different treatment between MNC and DC; b) to classify and to code the main 
characteristics of the selected articles - e.g., related theories, (in) dependent variables, data source, methodologies, authors, journals, etc.; c) to present a summary and contribution of the papers; d) to identify the main knowledge gaps and directions for future studies on the topic.

The other items in this study are organized as follows. The literature review is presented in section 2. In section 3, the methodology of bibliometric analysis and systematic review is detailed. The analysis of the results is detailed in section 4 . Finally, section 5 points out the main conclusions and limitations.

\section{Literature Review}

Do companies having consistent profits make an important decision regarding their destination - distribute them to shareholders or reinvest in assets? Thus, the dividend distribution policy generates agency conflict since shareholders prioritize the current return on their investments, while managers prioritize future returns by investing in new projects.

This conflict generates costs such as the monitoring of administrators by shareholders. Miller and Modigliani (1961) assume that there are no brokerage fees or transaction costs. However, there is a constant monitoring cost. An aversion to risk by managers is also observed, which encourages them to invest in safer projects. This behavior is opposed to the shareholders' one, who opt for riskier projects and, consequently, with greater potential for return (Easterbrook, 1984). In turn, Shao et al. (2010) state that the shareholder-manager relationship is not a zerosum game. The conflict between both implicates the company's performance, affecting collective interests and breaking the group's consonance.

The result obtained by Glendening et al. (2016) points to a reduction in the dividend payment in companies that: a) are in countries with consistent legal regimes, b) have a greater need for external financing, and c) have a weak system for monitoring the administrators. There is also evidence that companies' dividend distribution decreases after corporate reorganization events - e.g., their mergers or acquisitions business with large business groups or larger size companies.

For Brockman et al. (2014), companies use the dividend distribution policy to reduce informational asymmetry and agency costs. This fact stems from a possible institutional weakness of the countries in which these companies are located - e.g., legislation permissible with insider traders' action. Given this, these companies raise their payout ratio and encourage the pulverization of their property.

Hardin III and Hill (2008) clarify the role of dividend policy for real estate funds. These assets require additional capital from the debt and equity markets to grow. Therefore, the profit distribution is also relevant to mitigate eventual problems of agency conflicts. 
In turn, Pieloch-Babiarz (2019) identifies companies' structural features also influencing their dividend distribution policy. Those whose minority shareholders also play the role of managers have a higher payout ratio. Conversely, those whose majority shareholders participate in their management choose to retain and reinvest profits, prioritizing future returns.

Environments with a higher level of informational transparency encourage a higher dividend payment ratio. This occurs because the shareholders can more accurately assess the excess cash flow, facilitating their choice for the profit distribution at the meetings. In companies with a lower disclosure level, their managers need to signal their reputation to the market. Thus, they do so through higher payout levels (Brockman and Unlu, 2011).

The signaling theory presented by Lintner is the basis for several academic types of research. Changes in the dividend distribution policy may be an indicator for attentive investors. In the studies by Kim and Jang (2010), they point that accommodation and hospitality companies are extremely conservative when making changes to their dividend distribution policies, avoiding signaling volatility in their results.

In Poland, there are two different practices for implementing the dividend distribution policy. Among the companies regularly distributing dividends, the dominant ones are those constantly and increasingly doing so. This policy is desirable to long-term investors who expect to obtain returns by receiving dividends and the capital gain to be obtained in the future share sale. The companies taking different types of dividend policy differ in many aspects, especially in adopting an extreme and residual policy. This type of policy is more attractive to investors who long for capital growth (Pieloch-Babiarz, 2020).

The countries' different characteristics influence the companies' dividend distribution policy. In some countries, the predictability of dividends is evident due to the signaling observed. For Breuer et al. (2014), patience and loss aversion demonstrate influence in determining the differences among the countries chosen for investment. More recently, Breuer et al. (2017) suggest that managers tend to be more conservative in cash management in environments with uncertainties. For Ellsberg (1961), this more conservative view occurs even in companies with a higher disclosure level when there are reliability problems and agency conflict.

Companies have difficulties in justifying the cash accumulation since, a priori, the resources must be invested in future projects. However, if a company has a high liquidity ratio, additional cash accumulation is not justified, enabling a higher payout ratio (Breuer et al., 2017).

Several factors may contribute to the definition of the companies' dividend distribution policy - e.g., a) past dividend decisions, b) earnings, c) investment opportunities, d) profitability, e) free cash flow, f) corporate governance, g) 
company size and h) company structure. However, few studies investigate MNCs' influence versus DCs in determining the organizations' payout ratio (Bahreini et al., 2018, Baker et al., 2019, Dewasiri et al., 2019).

Ahktar (2018a) identifies that Australian, British, and Malaysian multinational companies pay significantly fewer dividends than equivalent companies not having assets or revenue outside their countries of origin - DCs. The American market is sensitive to changes in the tax rate, causing an impact on other countries and, mainly, on sending dividends remittances to other countries. Thus, the effect of a company's multinationality is considered a determining factor for distributing dividends between countries (Kopits, 1972, Rangvid et al., 2014).

The study by Bellak and Leibrecht (2010) shows that MNCs' higher tax rates on dividends have a negative effect on dividend repatriation. For each $1 \%$ tax rate reduction charged on DC's dividends, there is an increase of $3.75 \%$ in the dividends repatriated by them. For Tahir et al. (2020), fluctuations in credit supply and exchange rate influence the MNC's dividend distribution policy. Those geographically located in the United States repatriate fewer dividends from countries not having a solid credit market. Also, they actively manage foreign exchange risk through the dividend repatriation policy.

Kim and Jeon (2015) find empirical evidence that the Korean multinational subsidiaries' dividend policies are determined to meet the remittance requirements imposed by their parent companies. Such a fact highlights the existence of differences between DCs' dividend policies and MNCs' subsidiaries. Also, Harju and Kari (2017) find that, due to tax reform in Finland, there is a $23 \%$ increase in dividend payments, in addition to an increase in foreign profits repatriated to Finnish MNCs.

Huang et al. (2015) identify that MNCs and DCs' dividend distribution policy may also be affected by political risk. MNCs tend to have greater exposure to foreign risk, contributing to the variation in companies' dividend payments. Obviously, countries with more stable political systems and better legal protection for their investors reduce the political uncertainty level. This fact enables more stability in the dividend distribution policy of these organizations. Lai et al. (2020) verify that the negative relationship between stock market liquidity and dividends is more pronounced in countries with more solid political institutions.

Finally, Akhtar's (2018b) study points that MNCs pay significantly fewer dividends than DCs. Thus, the foreign involvement degree is an important determinant in the dividend distribution. MNCs are less likely to be dividend payers than DCs due to the fiscal disadvantage arising from the risk of exposure to tax laws in each country. Given the above, this study contributes to the research enrichment on MNCs and DCs cause on companies' dividend distribution policy. 


\section{Methodology}

This article aims at providing a bibliometric analysis and systematic review of the most relevant papers on MNCs and DCs' dividend distribution policy between January 1972 and August 2020. Bibliometric analysis refers to the study and classification of bibliographic material quantitatively. This method becomes more used in the state-of-the-art assessment of scientific disciplines, especially due to technological development. At first, it is applied to medical studies. However, more recently, it has been adopted in management, economics, and finance research (Merigo and Yang 2017). Alexander and Mabry (1994) and Borokhovich et al. (1995) present classifications about the most finance influential authors and institutions. Kim et al. (2009) investigate the competitive advantage of the main institutions and point out future trends. In turn, Borokhovich et al. (2000) and Currie and Pandher (2011) analyze the quality and influence of financial journals.

The systematic review originates in the nineties on medical topics, like bibliometric analysis. Subsequently, other fields of science adopt it, including studies on corporate finance. Martinez et al. (2018) propose the literature's presentation and organization on the capital structure through a systematic review. They use Scopus' database to analyze the small and medium-sized companies' capital structure financial theories. Kumar et al. (2019) carry out their research by considering both systematic review and bibliometric analysis methods. The database considered is Web of Science (WoS). The authors also look for knowledge gaps of small and medium-sized companies' capital structure. Also, in the corporate finance field, Barboza et al. (2016) present a systematic review of credit risk management. The authors classify and code the main studies using the articles' number of citations criterion.

According to Tranfield et al. (2003), the systematic review uses an explicit algorithm to carry out research and literature critical evaluations, employing a transparent and reproducible procedure. Generally, the review process consists of data collection, analysis, and synthesis, to identify knowledge gaps and point out future directions for further studies on the theme under analysis.

Thus, the main differences between bibliometric analysis and systematic review are that the former seeks to quantitatively analyze the papers' data - generating information on the number of citations, the relevance of publications, cooperation among authors, etc. The latter seeks to qualitatively analyze the data, evaluating how the information may point to future knowledge directions.

This study is developed through the steps presented below. Steps 1 to 5 meet the bibliometric analysis methodologies and systematic review, and steps 6 and 7 refer exclusively to systematic review.

Step 1 - The sample articles are obtained from WoS, which is the world leading citation database. 
Step 2 - To limit the study's scope, a keyword search is performed, as shown in Table 1. The initial sample has 117 papers, mentioned in Table 1, it also considers the application of the following WoS database' source-filters: a) language - English, b) type of material - full articles of journals, c) period - January 1, 1972, to August 12, 2020, and d) areas of concentration - finance; business and management. The papers with the greatest impact are identified according to the number of their citations, as mentioned in Step 3.

Table 1. Keywords for obtaining the initial sample

\begin{tabular}{|c|c|c|}
\hline Keywords & Derivations and complements & Number of papers \\
\hline "Dividend*” & AND "Multinat* Corporat*” & 26 \\
\hline "Dividend*" & AND "Multinat* Enterpris*” & 14 \\
\hline "Dividend"” & AND "Cross* Countr*" & 40 \\
\hline "Dividend* Polic*" & AND "Multinat* Corporat*” & 2 \\
\hline "Dividend* Polic*" & AND "Multinat* Enterpris*” & 3 \\
\hline "Dividend* Polic*" & AND "Cross* Countr*” & 8 \\
\hline "Payout*" & AND "Multinat* Corporat*" & 2 \\
\hline "Payout*" & AND "Multinat* Enterpris*” & 1 \\
\hline "Payout*" & AND "Cross* Countr*" & 12 \\
\hline "Dividen* Determinant*" & & 9 \\
\hline \multicolumn{2}{|l|}{ Initial sample } & 117 \\
\hline
\end{tabular}

Source: Own creation.

Step 3 - The exclusion of 27 repeated articles is performed. Afterward, an initial reading of the summary, introduction, and conclusion of the articles is made to verify whether they follow the defined theme - determinants of companies' dividend policy. Thus, from 90 articles in the intermediate sample, 67 are excluded due to the following reasons: a) dependent variables other than dividends, 4 of which refer to foreign investment, 4 to debt, and 43 to other diverse variables such as taxes, repatriation, and leverage, b) not obtaining 4 articles from the bases mentioned in Step 4; c) 12 conceptual articles not involving econometric models. Thus, the final sample consists of 23 articles.

Step 4 - From the final sample of 23 articles, the following information is collected to capture the general data of the article: title, author's name, affiliated institution and country of origin of the authors/researchers, journal name, volume, and edition number, start and end pages, year of publication, data country of origin and number of years of sample data, keywords, Digital Object Identifier (DOI), Journal of Economic Literature (JEL) and several article citations in the WoS database.

Step 5 - Using RStudio (version 1.2.1335), R (version 3.6.1), and VOSViewer software, objective data of articles - countries, authors, keywords, institutions, etc. - are analyzed for the preparation and analysis of tables and maps of relationship/co-citation. Among the possible analyses to be carried out - by table and map - are a) journals' influence and cocitations; b) sample authors' influence and citations; c) WoS database' authors' influence and citations; d) articles' influence and citations; e) authors' keywords; f) keywords of the references; g) contribution by countries. Also, these analyses are complemented by the verification of the main bibliometry laws: a) Zipf's Law (1949) - categorization and estimation of the frequency of the keywords with the aid of the Rank Words software for 
calculating Goffman's T point - transition point from low to high-frequency words, a region that theoretically concentrates high semantic load words, b) Bradford's Law (1934) verification of journals producing many articles, in contrast to those producing few papers on a determined theme and c) Lotka's Law (1926) - identification of researchers having a higher production frequency in a given knowledge area.

Step 6 - Identification of objectives, contributions, (in) dependent variables, method, sample, and article results. Also, they are classified and coded into categories and subcategories structured as shown in Table 2. Each of the 12 categories has non-exclusive subcategories. This means that the same article may be classified into more than one subcategory. Thus, the frequency count sum of the subcategories - for each category - totals 100\%. In the codification process, up to 3 subcategories per article are assigned to each category.

Table 2. Matrix of (sub) categorization

\begin{tabular}{|c|c|}
\hline Categories & Subcategories \\
\hline \multirow{6}{*}{$\begin{array}{l}\text { 1. Main theme / focus of the } \\
\text { study }\end{array}$} & A - Dividend policy \\
\hline & B - Multinational \\
\hline & C - Taxes \\
\hline & D - Political risk \\
\hline & E-Cash reserve \\
\hline & F - Others \\
\hline \multirow{10}{*}{ 2. Theories related to hypotheses } & A - Dividend irrelevance theory \\
\hline & B - Signaling theory \\
\hline & C - Bird in hand theory \\
\hline & D - Pecking-order theory (POT) \\
\hline & E - Agency theory \\
\hline & F - Free cash flow theory \\
\hline & G - Theory of taxes \\
\hline & H - Dividend life cycle theory \\
\hline & I - Catering Theory \\
\hline & $\mathrm{J}$ - Result and substitution agency theory \\
\hline \multirow{9}{*}{ 3. Method used } & A - Theoretical or conceptual \\
\hline & B - Case Study \\
\hline & C - Quantitative with cross-sectional data \\
\hline & D - Quantitative with time series data \\
\hline & E - Quantitative with panel data \\
\hline & F - Qualitative - empirical analysis \\
\hline & G - Simulation with computational methods \\
\hline & H - Application of questionnaires \\
\hline & I - Others \\
\hline \multirow{5}{*}{ 4. Dependent variables } & A - Dividends \\
\hline & B - Payout ratio \\
\hline & $\mathrm{C}$ - Past dividends \\
\hline & D - Propensity for dividend payments \\
\hline & E - Others \\
\hline \multirow{5}{*}{ 5. Independent variables } & A - Multinational companies \\
\hline & B - Domestic companies \\
\hline & $\mathrm{C}$ - Retained earnings \\
\hline & D - Political risks \\
\hline & E - Others \\
\hline \multirow{2}{*}{ 6. Types of data analyzed } & A - Financial statements \\
\hline & B - Market \\
\hline
\end{tabular}




\begin{tabular}{|c|c|}
\hline & C - Macroeconomic \\
\hline & D - Regulators \\
\hline & E - Financial Institutions \\
\hline & F - Others \\
\hline \multirow{7}{*}{ 7. Data origin } & A - Global \\
\hline & B - USA and Canada \\
\hline & C - Europe \\
\hline & D - Asia/Oceania \\
\hline & E - Latin America \\
\hline & F - Africa \\
\hline & G - Others/ Not mentioned \\
\hline \multirow{3}{*}{ 8. Economic context } & A - Developed country \\
\hline & B - Undeveloped / emerging country \\
\hline & C - Both \\
\hline \multirow{5}{*}{ 9. Analysis period } & A - Up to 3 years \\
\hline & B - From 3 to 5 years \\
\hline & C - From 6 to 10 years \\
\hline & D - More than 10 years \\
\hline & E - Not applicable \\
\hline \multirow{4}{*}{ 10. Results } & A - New perspectives \\
\hline & B - Similar conclusions to works previously presented \\
\hline & C - New conclusions \\
\hline & D - Others \\
\hline \multirow{4}{*}{$\begin{array}{l}11 . \quad \text { Conclusion on the } \\
\text { hypotheses }\end{array}$} & A - Confirmation of the main hypothesis \\
\hline & B - Non-confirmation of the main hypothesis \\
\hline & $\mathrm{C}$ - Non-conclusive result related to the main hypothesis \\
\hline & D - Not applicable \\
\hline \multirow{5}{*}{ 12. Directions for future studies } & A - Share buyback \\
\hline & B - Influence of the country's culture on its economy \\
\hline & C - Repatriation of profits and dividends \\
\hline & D - Mergers and acquisitions \\
\hline & E - Triangulation approach \\
\hline
\end{tabular}

Source: Own creation.

Step 7 - After coding the (sub) categorization matrix - for the final sample - a frequency count of the subcategories is performed to identify knowledge gaps. These gaps are then compared with the subcategories of category 12 - directions for future studies - to obtain aspects that may be subject to further studies on the topic. In Figure 6, the individual subcategories, or their combinations - by category indicate the highest and lowest frequencies of interest on the topics presented. In this case, the total number of articles in the final sample is $100 \%$.

\section{Findings and Discussions}

The results presented below refer to the bibliometric analysis - see steps 1 to 5 of the methodology - and systematic review - see steps 6 and 7 of the methodology. Both checks are performed for the final sample of 23 articles. 


\subsection{Bibliometric Analysis}

The final sample consists of 23 articles analyzed and classified as articles published in journals. These have unpublished conclusions due to a new fact found by their authors. Their main features are presented below.

As mentioned, the research period is from January 1, 1972, to August 12, 2020. Figure 1 indicates no research on the themes of dividends and MNCs in the interval between 1973 and 2007. The topics on dividend policy and MNCs become more published as of 2010, with an annual average of 3 publications between 2010 and 2020.

Figure 1. Chronological frequency of papers' publication

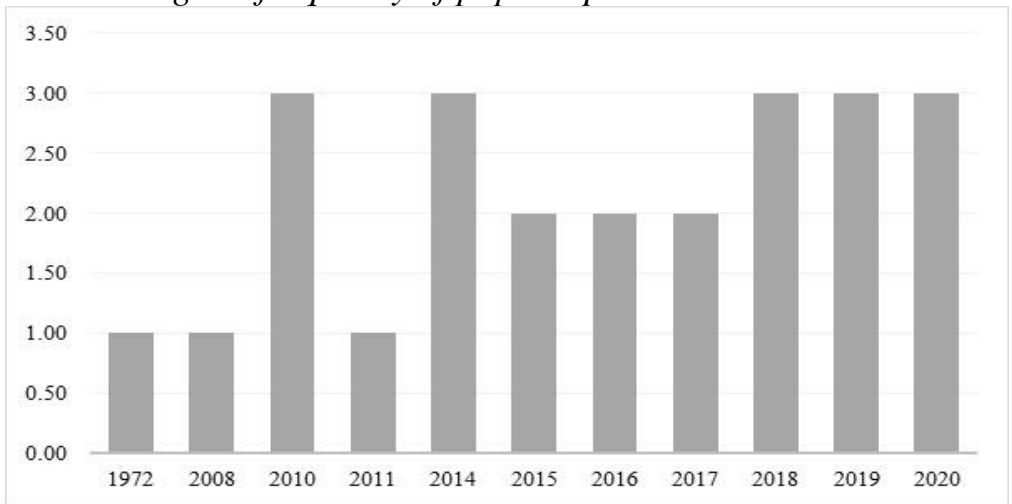

Source: Own creation.

Figure 2 presents a co-occurrence map of the most cited keywords in the 23 papers of the final sample, obtained through the VOSviewer software. The most frequent words refer to dividend policy (12) and dividend determinants (3). The other keywords appear once or twice.

In the sequence, the "m" index (Banks 2006) is calculated from the keywords using the following categories: a) Dividend distribution policy, b) Multinational companies, c) Other determinants of dividend distribution policy, d) Theories on dividend distribution policy, e) Methodological approach and f) Sample of companies.

The referred index is calculated by dividing the " $h-b$ " index by the period of years one wants to obtain information - see Equation 1. For Banks (2006), the h-b index is an extension of the " $h$ " index, proposed by Hirsch (2010), for the analysis of a researcher's scientific production. The " $h-b "$ index is obtained by the number of citations of a topic or combination in a given period, listed in decreasing order of citations.

"m" index $=$ " $\mathrm{h}-\mathrm{b}$ " index / $\mathrm{t}$ 
Where:

"h-b" index = "h" index provided by WoS by topic

$\mathrm{t}=$ Last year minus first year of publication of the topic

Figure 2. Keywords co-occurrence map

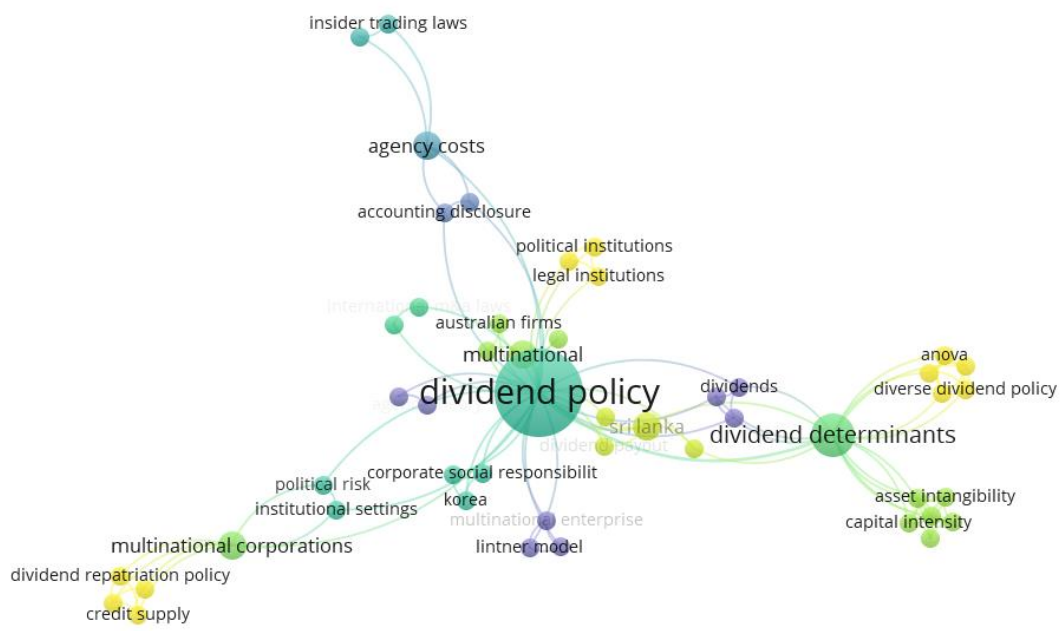

Note: The size of the nodes refers to the number of times the keyword is repeated in articles. The color of the nodes corresponds to the number of citations and the occurrences of keywords in publications.

Source: VOSviewer Software.

The criteria for the analysis of the "m" index are a) $0<\mathrm{m} \leq 0.5$ - it is restricted to a specific area of knowledge, involving a small community of researchers, b) $0.5<\mathrm{m}$ $\leq 2$ - it may become a hot topic due to its interest by a large community of researchers or because it has significant features, c) $\mathrm{m} \geq 2$ - it is a hot topic because it is interesting not only to its own area of knowledge but also because it has an application or unique characteristics, having importance to a large community of researchers.

According to the mentioned criteria, for the main categories of dividend distribution policy and multinational companies, the keywords representing hot topics $(\mathrm{m} \geq 2)$ are dividend and multinational corporations/enterprises. Regarding other determinants of dividend distribution policy, ownership structure, firm size, board composition, board independence, and national culture are highlighted. The theories that most support the hypotheses related to these determinants are loss aversion, agency theory, information asymmetry, and agency costs. There is no identification of hot topics for the categories methodological approach and sample of companies whose $m$ indexes have values less than 2 .

Zipf's Law (1949) allows estimating the frequencies of word occurrence in scientific texts and delimiting the region of concentration of indexing terms. A small group of 
words may occur many times, while a large number of words may have a low frequency (Guedes 2012). Zipf's first law states that the product of the serial order (r) of a word by its frequency of occurrence (f) is approximately constant (C), resulting in Equation 2:

$$
\mathrm{rxf}=\mathrm{C}
$$

For Fairthone (1969), Zipf's law is the least effort law, being elegant for its simplicity. However, it applies only to words with a high-frequency occurrence in a text. Zipf proposed a second law for low-frequency words, which was revised and modified by Booth (1967). According to the author, in a given text, several words with low-frequency occurrence have the same assiduity - see Equation 3:

$$
\mathrm{I}_{\mathrm{n}}=2 \mathrm{I}_{1} / \mathrm{n}(\mathrm{n}+1)
$$

Where:

I1 = number of words having frequency 1

In = number of words having frequency $n$

$\mathrm{n}=$ Goffman's point or place of transition from low to high frequency words

Zipf's laws define the ends of a word distribution list. Between these extreme points, there is a transition region from high to low frequency words.

According to Goffman (1971), in this region are the words with the highest semantic content, which are the most suitable for the thematic indexing of a given text. Pao (1978) presents the formula for the T point or Goffman's transition point see Equation 4.

$$
\mathrm{T}=\left(-1+\sqrt{1+8 \mathrm{I}_{1}}\right) / 2
$$

Where:

$\mathrm{T}=$ Goffman's transition point

$\mathrm{I}_{1}=$ number of words having frequency 1

After analyzing the articles in the final sample, the Rank Words software provides a list of words in decreasing order of frequency. In the sequence, repeated only once are identified for the calculation of Goffman's T point. Then, those words above the classification indicated by this point are located. The result shows that, for the 23 articles, this point varies between 20.29 (Brockman et al., 2014) and 49.30 (Breuer et al., 2014), with an average of 40.17 .

After calculating Goffman's T-point for each article, one can analyze the region where the most compatible words with the main theme of the text are. Those irrelevant to the study are excluded - e.g., prepositions, (in) definite articles, pronouns, and adverbs. Subsequently, the highest frequency words are classified. In the paper by Rangvid et al. (2014), the word dividend has the highest frequency; 
that is, it is repeated 296 times in a text with 13,779 words. Also, the word dividend is verified as being present in 14 out of the $23(61 \%)$ papers in the final sample. Words such as cash, political, tax, excess, shareholders, repatriation, disclosure, and trading also have a high frequency in the $9(39 \%)$ other articles in the final sample.

As for the authorship of the articles, 58 authors are identified, from which 3 publish them individually, and 55 are co-authors. As for the decreasing ranking of the 16 countries of the institutions to which the authors are associated, among the 58 authors, $15(26 \%)$ are related to institutions located in the United States, $7(12 \%)$ in Sri Lanka, 6 (12\%) in Germany, 5 (9\%) in China, $3(5 \%)$ in Australia, $3(5 \%)$ in Hong Kong, 2 (3\%) in Austria, 2 (3\%) in South Korea, 2 (3\%) in Malaysia, 2 (3\%) in Poland, $2(3 \%)$ in Turkey, $2(3 \%)$ in Pakistan and $2(5 \%)$ in Finland. The remaining $5(9 \%)$ authors are linked to institutions located in Denmark, England, Tunisia, Switzerland, and New Zealand.

Out of the 23 articles, 5 (22\%) are classified by RStudio software as single country publications - they are written and published by authors from the same country, while $18(78 \%)$ are considered multiple country publications more than one country write them. Despite this fact, 225 (71\%) citations occur for articles written by authors associated with institutions located in the United States. The remaining citations refer to authors whose entities are in the following countries: 30 (10\%) Australia, 24 (8\%) - Denmark, 24 (8\%) - Germany, 12 (3\%) - South Korea, Austria, and Finland. These results are corroborated by Figure 3.

The journal with the most publications (3) in the sample is the Journal of International Studies, followed by Accounting and Finance, Journal of Banking and Finance, and Managerial Finance, with 2 publications each. In turn, Figure 4 shows the journals with the most co-citations in the final sample of 23 articles, which are Journal of International Business Studies, Accounting, and Finance, Journal of Banking and Finance, and Managerial Finance. As for the other 14 journals, all of them have only 1 paper with themes related to dividends and multinationals.

Bradford's law (1934) states that few journals produce many papers, and many journals producing few papers on a given topic. For Brookes (1969), this law estimates certain academic journals' relevant degrees working in specific knowledge areas. Thus, if journals are classified in decreasing productivity order, they may be distributed in zones having a variation in the proportion $1: \mathrm{n}: \mathrm{n}^{2}$ and so on.

These zones are formed by dividing the total number of published articles by three. Zone $\mathrm{A}$ is identified as the core of the issues, and it is made up of journals producing more than four references per year. Zone B contains journals producing more than one and no more than four references annually. Finally, in zone $\mathrm{C}$ are the journals producing one of the least references per year. Among the 23 articles in the sample, $30 \%$ of publications on dividends are in zone $\mathrm{A}$, and this percentage is limited to only 3 academic journals - Journal of International Business Studies, Accounting and Finance, Journal of Banking and Finance. 
Figure 3. Map of citations of papers from countries of the institutions to which the authors are associated

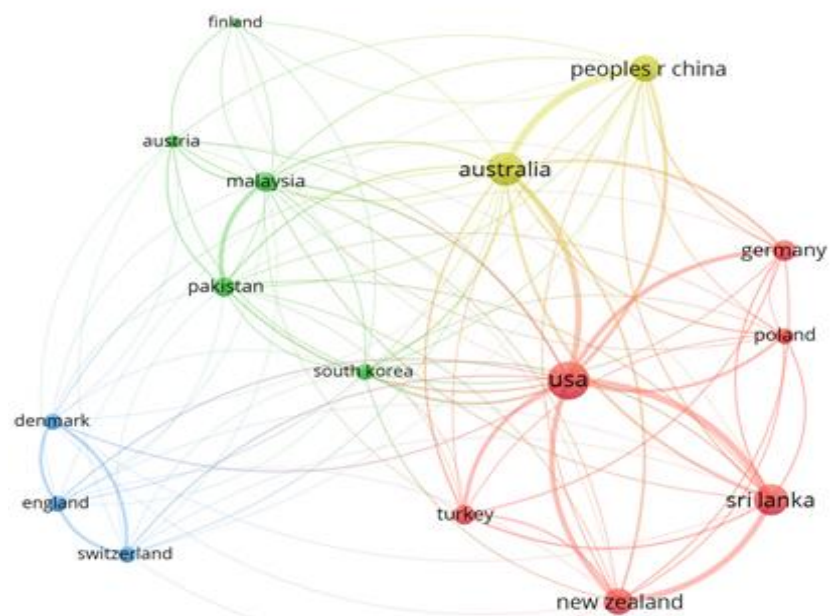

Note: The size of the nodes corresponds to the number of citations times the number of articles. The color of the nodes corresponds to the number of citations associated with the institutions and to the occurrences of co-authorship in publications among countries, with 4 citation clusters being defined among the authors: 1) Germany, New Zealand, Poland, Sri Lanka, Turkey and the United States; 2) Austria, Finland, Malaysia, Pakistan and South Korea; 3) Denmark, England and Switzerland and 4) Australia and China.

Source: VOSviewer Software.

Figure 4. Map of co-citations among journals

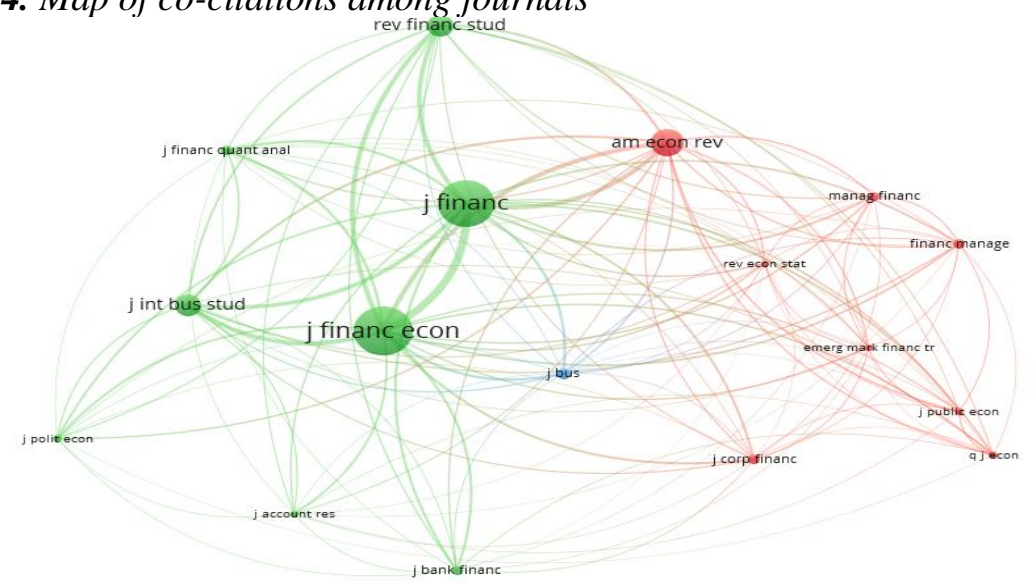

Note: The size of the nodes represents the ratio between the number of articles per journals and the number of citations. The color of the nodes corresponds to the groups formed by a set of journals, with the identification of 3 clusters.

Source: VOSviewer Software.

Table 3 presents the ten most cited papers on dividends and multinationals' themes, according to an analysis carried out using RStudio software. The most cited paper in the final sample has almost twice as many citations as the second and was written by Shao et al. (2010). Also, its annual average oAlsois 11 papers. It examines how 
culture affects companies' dividend policies, contributing to still unresolved issues on this topic. While most research concentrates on explanations based on theories such as agency, information asymmetry, and POT, this article uses cultural dimensions and conservative behaviors, analyzing a sample of 27,465 companies from 21 countries between 1995 and 2007. The remaining papers are positioned with less than 50 total citations and an annual average of citations below 5 .

Table 3. Ten most cited papers

\begin{tabular}{|l|l|c|c|}
\hline $\mathbf{N}^{\mathbf{0}}$ & References & Citations & $\begin{array}{c}\text { Annual average of } \\
\text { citations }\end{array}$ \\
\hline 1st & Shao et al., 2010 & 110 & 11.00 \\
\hline 2nd & Hardin III and Hill, 2008 & 49 & 4.08 \\
\hline 3rd & Brockman and Unlu, 2011 & 33 & 3.66 \\
\hline 4th & Huang et al. 2015 & 28 & 5.60 \\
\hline 5th & Rangvid et al., 2014 & 24 & 4.00 \\
\hline 6th & Breuer et al., 2017 & 22 & 3.66 \\
\hline 7th & Brockman et al., 2014 & 14 & 2.33 \\
\hline 8th & Kim and Jang, 2010 & 11 & 1.10 \\
\hline 9th & Kopits, 1972 & 11 & 0.23 \\
\hline 10th & Kim and Jeon, 2015 & 7 & 1.40 \\
\hline
\end{tabular}

Source: Own creation.

Figure 5 shows the nine most productive authors with the identification of three clusters. The criterion used by the VOSviewer software considers the number of citations that each author has on the WoS database, multiplied by the number of papers published by the same author with a similar theme. Each mentioned author has 2 papers on the topic of dividends and multinationals. This fact makes the authors stand out about those in Table 3 .

Figure 5. Map of the eight most productive authors

$$
\text { unlu, emre }
$$

brockman, paul

pieloch-babiarz, aleksandra

akhtar, shumi dewasiri, n. jayantha

azeez, athambawa abdul

soypak, k. can

koralalage, weerakoon banda ya

breuer, wolfgang

Note: The size of the nodes represents the number of papers published by author. The color of the nodes corresponds to the citation among the authors of the papers analyzed in the final sample.

Source: VOSviewer Software. 
Lotka (1926) presents the inverse-square law, known for proposing that a restricted number of academic researchers has a high frequency of production in a given area of knowledge. Conversely, a large volume of academic researchers produces little. Thus, Lotka (1926) identifies that the production obtained by this small number of researchers is quantitatively equal to the performance of the others. Equation 5 presents the application of Lotka's law.

$$
\mathrm{a}_{\mathrm{n}}=\mathrm{a}_{1} / \mathrm{n}^{2}, \mathrm{n}=1,2,3 \ldots
$$

Where:

$\mathrm{a}_{\mathrm{n}}=$ number of authors who published $\mathrm{n}$ papers

$\mathrm{a}_{1}=$ number of authors who published one article

$\mathrm{n}=$ number of published papers by author

In Equation 6, Chung and Cox (1990) clarify that the number of authors with a single published paper, according to Lotka's law, would be:

$\mathrm{a}_{1}=6 / \pi^{2}=0.6079=60.8 \%$

Thus, an author with two published papers should have a frequency of $15.2 \%$ $(0.6079 / 22)$. For an author with three published papers, it would be $6.8 \%$ $(0.6079 / 32)$. Table 4 shows the quantity and percentage of papers published by the sample authors. The standard values of Lotka's law are shown in the last column. It appears that, in fact, there is a lower percentage of authors publishing a greater number of articles, which confirms Lotka's law. Out of the 58 authors, 10 (17.24\%) are responsible for publishing 2 articles related to MNCs' impact on dividend distribution policy. Another $48(82.75 \%)$ publish a single article related to this theme, which characterizes even lower productivity than the standard reference obtained by Lotka $(60.79 \%)$.

Table 4. Lotka's Law application

\begin{tabular}{|c|c|c|c|}
\hline No. of papers & No. of authors & \% Authors & \% Lotka $(\mathbf{c}=2)$ \\
\hline 1 & 48 & 82.75 & 60.79 \\
\hline 2 & 10 & 17.24 & 15.19 \\
\hline Total & 58 & 100 & 75.99 \\
\hline
\end{tabular}

Source: Own creation.

\subsection{Systematic Review}

The literature systematic review goes beyond the bibliometric analysis, seeking to answer a question that signals knowledge gaps on a given topic - What is the impact of companies having assets and revenues outside their country of origin on their dividend distribution policy? For such, a matrix of (sub) categorization presented in Step 6 of the Methodology is defined - see Table 2. 
Subsequently, a frequency count of the subcategories is performed to enable the identification of knowledge gaps. Worth mentioning is that the same category may contain up to 3 subcategories. Therefore, the subcategories' frequency count sum for each category - totals $100 \%$ and not 23 articles in the final sample. These gaps are then compared with the subcategories of category 12 - directions for future studies to obtain aspects that may be further studied on the topic (Jabbour 2013, Barboza et al. 2016, Nazario et al. 2017).

Figure 6 shows the highest and lowest interest frequencies on multinational and domestic companies' impact on the dividend distribution policy. The subcategories are presented individually or in combination. Thus, for each category, the 23 articles in the final sample account for $100 \%$ of the frequencies. According to Jabbour (2013), the combined approach tends to produce even more original results. Those subcategories with less frequency suggest other researchers fill possible knowledge gaps.

Regarding category 1 , despite a relative recurrence of studies on dividend policy (A), there is no equal interest in the impact of the cash reserve (A-E) or taxes (A-C) on the companies' payout ratio. In turn, multinational companies and political risk have a greater interest by the academy. As for category 2 , the opportunity to analyze signaling theory combined with the agency theory (B-E) or the bird-in-hand theory (B-C) stands out. The analysis of the theme based on the agency's association, taxes, and catering theories (E-G-I) deserves the equal distinction. The hypotheses of the articles by Dewasiri et al. (2019) and Baker et al. (2019) are supported by seminal theories and by more recent ones. This fact results from the inclusion of unconventional determinants of dividend distribution policy - e.g., taxes, MNCs, the country's cultural influence, etc.

Regarding category 3, there is an unequivocal preference for using econometric models with panel data (E). This fact characterizes a window of opportunity for the use of other econometric models or even qualitative methods. As for category 4, much is studied about the distribution or not of dividends currently (A). However, little is examined about what influences their payment in previous fiscal years (B-C) or their propensity for distribution in the future (B-D).

For category 5, retained earnings (C) are the traditional determinants of most frequent use, corroborating the future research agenda for those that are not conventional - such as multinational (A) and domestic (B) companies. This result corroborates the analyses of category 1 . Also noteworthy is that even the papers having MNCs as determinants of the dividend distribution policy do so with a focus on the parent company and not on the perspective of its subsidiaries (DCs).

In category 6 , there is a predominance of secondary data extracted from the financial statements (A). Thus, data obtained from other sources may differ in research - e.g., market, macroeconomic, regulatory, financial institutions data, etc. Regarding the origin of the data, category 7 points out that it focuses on information 
from global companies (A) or located in Europe (C), Asia/Oceania (D), and the United States (B). It should be noted that there is no research on MNCs in countries in Latin America or Africa. This fact legitimizes the result of category 8. Almost half of the papers use data from companies in developed countries (A), with fewer studies focusing on analyzing emerging markets (B), despite their growing relevance in the world economy.

As for the samples' time horizon, category 9 indicates that most of them refer to long-term studies, with more than 10 years (D) or between 6 and 10 years (C). This period is in line with the econometric regression model with panel data - see category 3. The use of different methodologies may consider the adoption of different periods in the sample. Regarding category 10, most studies have similar conclusions to the previous ones (B). The research agenda points to studies presenting a higher degree of novelty with new perspectives (A) or conclusions (C).

As far as the validation of the hypotheses in category 11 is concerned, the overwhelming majority of the research is verified as confirming them (A), with a few presenting inconclusive results $(\mathrm{C})$. An example is a study by Kim and Jang (2010). By looking at the positive impact of investment opportunities on dividend payments, they identify a conflict between POT and agency theories. Thus, they propose adopting an alternative dividend model that helps consolidate the company's reputation and improves the shareholders' treatment in the capital markets.

Finally, category 12 presents the directions for future studies highlighted in the conclusion of the sample articles. The influence of the country's culture on its economy is highlighted (B), which, in turn, impacts the companies' dividend distribution policy. Other topics with similar less frequency are share buyback (A), repatriation of profits (C), mergers and acquisitions (D), and the triangulation approach (E).

Given the above, as potential themes to be inserted in an agenda of future studies are identified the verification of the aspects causing a difference between the MNCs and DC's dividend distribution policies, as well as of macroeconomic factors stimulating the repatriation of dividends by MNCs - e.g., exchange rate, credit supply and other features of each country. Another aspect highlighted is the need for studies aiming at emerging countries - notably in Latin America - given their growing relevance in the world economy. Finally, the importance of adopting econometric methods - different from panel data regression - is highlighted, which enable unprecedented results on the subject. 
Figure 6. Analysis of (sub) categories to identify knowledge gaps

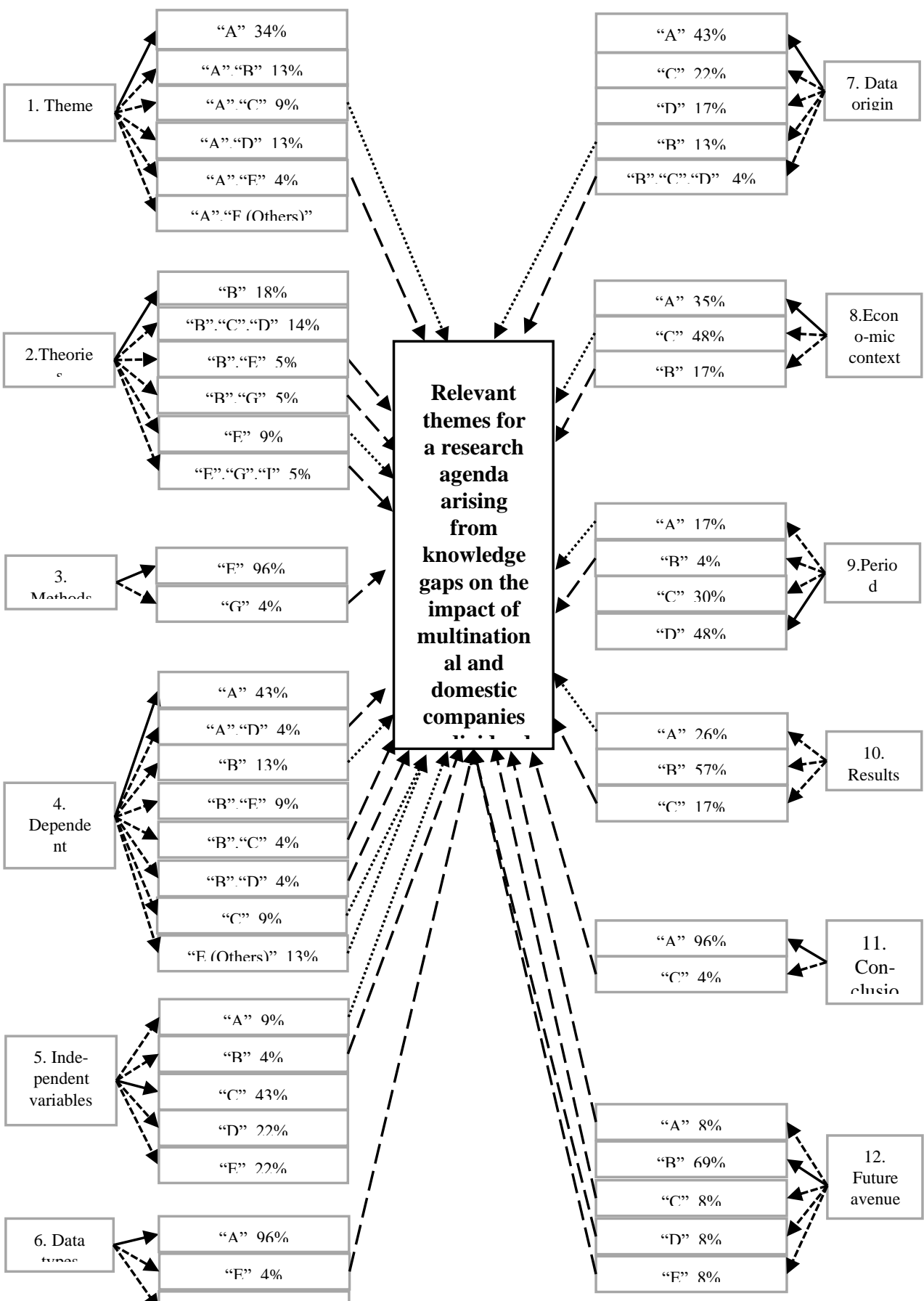




\section{Legend:}

Subcategory most frequently in each category

Subcategory with secondary frequency in each category

Subcategory to be prioritized in the research agenda

Subcategory to be considered as secondary on the research agenda

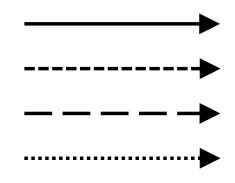

Source: Own creation.

\section{Conclusion}

Recently, the determinants of the MNCs' dividend distribution policies have aroused interest researchers in several countries. Such a fact is due to the opening of foreign branches due to globalization and the search for better countries' economic growth rates. Despite the existence of studies on the theme, there is a need for a systematic review of the literature on multinational and domestic companies' impact on the dividend distribution policy. This analysis allows identifying a research agenda resulting from knowledge gaps on the topic, characterizing the main contribution of this study.

To this end, both bibliometric analysis and systematic review methods are adopted with the final sample of 23 articles. The former refers to a quantitative analysis developed by counting frequencies and co-citations. The latter refers to a qualitative analysis, looking for the correlation between relevant themes, although still little explored by the academy. These papers are obtained from the WoS database. The adoption of both methods requires software such as RStudio, R, VOSViewer, and Rank Words. In the bibliometric analysis, the verification of its main laws, such as Zipf (1949), Bradford (1934), and Lotka (1926), is also adopted.

Among the results obtained by the bibliometric analysis, it appears that dividends are presented as a hot topic or high-frequency keyword. Most studies occur in educational institutions located in the United States, being published mainly in the Journal of International Studies. According to Bradford's law, the journals with the highest number of citations are the Journal of International Business Studies, Accounting and Finance, and Journal of Banking and Finance. Among the most cited papers, Shao et al. (2010), with an annual average citation of 11 articles, is highlighted. It examines how culture affects companies' dividend policies, contributing to unresolved issues on this topic. Finally, Lotka's law states that $83 \%$ of authors have only one published article.

In turn, the systematic review points out the comparative study of the dividend distribution policy between MNCs and DCs as an object of interest. An example is that the exchange rate devaluation in a given country may impact the percentage of dividend distribution between both types of companies. In this case, relevance is the understanding of the distinction between MNCs - those having investments in capital goods abroad - from those having the majority of their income originated by their foreign subsidiaries. Another important aspect is the analysis of exchange rate 
fluctuations and credit supply in countries where MNCs' assets are located. Repatriation of dividends is essential in a scenario where global business chains increase linearly.

As for this study's limitations, the results presented refer to the set of articles from the journals meeting the established selection criteria and the database used (WoS). The analysis of papers exclusively with empirical tests may have excluded studies with mathematical modeling, research, and essays also having relevant contributions. Thus, the expansion of this study, disregarding the aforementioned limiting factors, is suggested and the inclusion of atypical scenarios - such as those caused by Covid-19. This pandemic has put an apparent brake on the globalization process, making international logistics and reliance on single suppliers more difficult. This fact compels the approach of input production to transforming industries and to local consumers.

\section{References:}

Akhtar, S. 2018a. Dividend policies across multinational and domestic corporations - an international study. Accounting and Finance 58(3), 669-695. https://doi.org/10.1111/acfi.12179.

Akhtar, S. 2018b. Dividend payout determinants for Australian multinational and domestic corporations. Accounting and Finance 58(1), 11-55. https://doi.org/10.1111/acfi.12137.

Alexander Jr, J.C., Mabry, R.H. 1994. Relative significance of journals, authors, and articles cited in financial research. Journal of Finance, 49(2), 697-712. https://doi.org/10.1111/j.1540-6261.1994.tb05158.x.

Bahreini, M., Adaoglu, C. 2018. Dividend payouts of travel and leisure companies in Western Europe: an analysis of the determinants. Tourism Economics, 24(7), 801820. https://doi.org/10.1177/1354816618780867.

Baker, H.K., Dewasiri, N.J., Koralalage, W.B.Y., Azeez, A.A. 2019. Dividend policy determinants of Sri Lankan firms: a triangulation approach. Managerial Finance 45(1), 2-20. https://doi.org/10.1108/MF-03-2018-0096.

Banks, M.G. 2006. An extension of the Hirsch index: Indexing scientific topics and compounds, Scientometrics, 69(1), 161-168. https://doi.org/10.1007/s11192-0060146-5.

Barboza, F., Kimura, H., Sobreio, A.V., Basso, L.C. 2016. Credit risk: from a systematic literature review to future directions. Corporate Ownership and Control, 13(3), 326346. https://doi.org/10.22495/cocv13i3c2p6.

Bellak, C., Leibrecht, M. 2010. Does lowering dividend tax rates increase dividends repatriated?. Evidence of intrafirm cross-border dividend repatriation policies by German multinational enterprises Finanzarchiv, 24, 27-45. https://doi.org/10.2139/ssrn.1672689.

Borokhovich, K.A., Bricker, R.J., Brunarski, K.R., Simkins, J.B. 1995. Finance research productivity and influence. Journal of Finance 50(5), 1691-717. https://doi.org/10.1111/j.1540-6261.1995.tb05193.x.

Borokhovich, K.A., Bricker, R.J., Simkins, B. 2000. An analysis of finance journal impact factors. Journal of Finance 55(3), 1457-1469. https://doi.org/10.1111/00221082.00254 . 
Booth, A.D.A. 1967. A "law" of occurrences for words of low frequency. Information and Control, 10(4), 386-393. https://doi.org/10.1016/S0019-9958(67)90201-X.

Bradford, S.C. 1934. Sources of information on scientific subjects. Engineering: An Illustrated Weekly Journal, 137, 85-86. https://doi.org/10.1177/016555158501000407.

Breuer, W., Rieger, M.O., Soypak, K.C. 2014. The behavioral foundations of corporate dividend policy a cross-country analysis. Journal of Banking and Finance, 42, 247265. https://doi.org/10.1016/j.jbankfin.2014.02.001.

Breuer, W., Rieger, M.O., Soypak, K.C. 2017. Corporate cash holdings and ambiguity aversion. Review of Finance, 21(5), 1933-1974. https://doi.org/10.1093/rof/rfw025.

Brockman, P., Unlu, E. 2011. Earned/contributed capital, dividend policy, and disclosure quality: an international study. Journal of Banking and Finance, 35(7), 1610-1625. https://doi.org/10.1016/j.jbankfin.2010.11.014.

Brockman, P., Tresl, J., Unlu, E. 2014. The impact of insider trading laws on dividend payout policy. Journal of Corporate Finance 29, 263-287. https://doi.org/10.1016/j.jcorpfin.2014.09.002.

Brookes, B.C. 1969. Bradford's law and the bibliography of science. Nature, 222, 953-956. https://doi.org/10.1038/227631a0.

Chung, K.H., Cox, R.A.K. 1990. Patterns of productivity in the finance literature: a study of the bibliometric distributions. Journal of Finance, 45(1),301-309. https://doi.org/10.1111/j.1540-6261.1990.tb05095.x.

Currie, R.R., Pandher, G.S. 2011. Finance journal rankings and tiers: an active scholar assessment methodology. Journal of Banking and Finance, 35(1), 7-20. https://doi.org/10.1016/j.jbankfin.2010.07.034.

Dewasiri, N.J., Koralalage, W.B.Y., Azeez, A.A., Jayarathne, P.G.S.A., Kuruppuarachchi, D., Weerasinghe. V.A. 2019. Determinants of dividend policy: evidence from an emerging and developing market. Managerial Finance, 45(3), 413-429. https://doi.org/10.1108/MF-09-2017-0331.

Easterbrook, F.H. 1984. Two agency-cost explanations of dividends. American Economic Review, 74(4), 650-659. Retrived from: https://www.jstor.org/stable/1805130?seq=1.

Ellsberg, D. 1961. Risk, ambiguity, and the savage axioms. Quarterly Journal of Economics, 75(4), 643-669. https://doi.org/10.2307/1884324.

Fairthone. R.A. 1969. Empirical hyperbolic distribution (Bradford - Zipf - Mandelbrot) for bibliometric description and prediction. Journal of Documentation, 25(4), 521-534. https://doi.org/10.1108/eb026481.

Glendening, M., Khurana, L.K., Wang, W. 2016. The market for corporate control and dividend policies: cross-country evidence from M\&A laws. Journal of international Business Studies, 47(9), 1106-1134. https://doi.org/10.1057/s41267-016-0028-x.

Goffman, W. 1971. A mathematical method for analyzing the growth of a scientific discipline. Journal of Association for Computing Machinery, 18(2), 173-185. https://doi.org/10.1145/321637.321640.

Gordon, M.J. 1959. Dividends, earnings, and stock prices. Review of Economics and Statistics, 41(2), 99-105. http://dx.doi.org/10.2307/1927792.

Gordon, M.J. 1963. Optimal investment and financing policy., Journal of Finance, 28(2), 264-272. https://doi.org/10.1111/j.1540-6261.1963.tb00722.x.

Guedes, V.L.S. 2012. A bibliometria e a gestão da informação e do conhecimento científico e tecnológico: uma revisão da literatura. Ponto de Acesso, 6(2), 74-109. https://doi.org/10.9771/1981-6766rpa.v6i2.5695. 
Hardin III, W., Hill, M.D. 2008. REIT dividend determinants: excess dividends and capital markets. Real Estate Economics 36(2), 349-369. https://doi.org/10.1111/j.15406229.2008.00216.x.

Harju, J. Kari, S. 2017. Dividend taxes and decisions of MNEs: evidence from a Finnish tax reform. Cesifo Economic Studies, 63(1), 45-77. https://doi.org/10.1093/cesifo/ifw001.

Hirsch, J.E. 2010. An index to quantify an individual's scientific research output that takes into account the effect of multiple coauthorship. Scientometrics, 85, 741-754. https://doi.org/10.1007/s11192-010-0193-9.

Huang, T., Wu, F., Yu, J., Zhang, B. 2015. Political risk and dividend policy: evidence from international political crises. Journal of International Business Studies 46(5), 574595. https://doi.org/10.1057/jibs.2015.2.

Jabbour, C.J.C. 2013. Environmental training in organisations: From a literature review to a framework for future research. Resources, Conservation and Recycling, 74, 144155. https://doi.org/10.1016/j.resconrec.2012.12.017.

Kim, E.H., Morse, A., Zingales, L. 2009. Are elite universities losing their competitive edge? Journal of Financial Economics, 93(3), 353-81. https://doi.org/10.1016/j.jfineco.2008.09.007.

Kim, J., Jang, S. 2010. Dividend behavior of lodging firms: Heckman's two-step approach. International Journal of Hospitality Management, 29(3), 413-420. https://doi.org/10.1016/j.ijhm.2009.08.009.

Kim, J., Jeon, Y. 2015. Dividend policy and corporate social responsibility: a comparative analysis of multinational enterprise subsidiaries and domestic firms in Korea. Emerging Markets Finance and Trade, 51(2), 306-319. https://doi.org/10.1080/1540496X.2015.1021605.

Kopits, G.G. 1972. Dividend remittance behavior within international firm - cross-country analysis. Review of Economics and Statistics, 54(3), 339-342. https://doi.org/10.2307/1937999.

Kumar, S., Sureka, R., Colombage., S. 2019. Capital structure of SMEs: a systematic literature review and bibliometrics analysis. International Journal of Managerial Finance, 13(2), 106-132. https://doi.org/10.1111/j.1467-6486.2006.00625.x.

Lai, K.M.Y., Saffar, W., Zhu, X. Liu, Y. 2020. Political institutions, stock market liquidity and firm dividend policy: Some international evidence. Journal of Contemporary Accounting and Economics, 16(1), 1-20. https://doi.org/10.1016/j.jcae.2019.100180.

Lintner, J. 1962. Dividends, earnings, leverage, stock prices and the supply of capital to corporations. Review Economics and Statistics, 44(3), 243-269. https://doi.org/10.2307/1927792.

Lotka, A.J. 1926. The frequency distribution of scientific productivity. Journal of the Washington Academy of Sciences, 16(12), 317-323.

Martinez, L.B., Scherger, V. Guercio, M.B. 2018. SMEs capital structure: trade-off or pecking order theory: a systematic review. Journal of Small Business and Enterprise Development, 26(1), 105-132. https://doi.org/10.1108/JSBED-12-20170387.

Merigo, J.M., Yang, J. 2017. Accounting research: a bibliometric analysis. Australian Accounting Review, 27(1), 71-100. https://doi.org/10.1111/auar.12109.

Miller, M.H., Modigliani, F. 1961. Dividend policy, growth and the valuation of shares. Journal of Business, 34(4), 411-433. https://doi.org/10.1086/294442. 
Nazário, R.T.F., Lima e Silva, J., Sobreiro, V.A., Kimura, H. 2017. A literature review of technical analysis on stock markets. The Quarterly Review of Economics and Finance, 66, 115-126. https://doi.org/10.1016/j.qref.2017.01.014.

Pao, M.L. 1978. Automatic text analysis based on transition phenomena of word occurrences. Journal of the American Society for Information Science, 29(3), 121124, https://doi.org/10.1002/asi.4630290303.

Pieloch-Babiarz, A. 2019. Ownership structure, board characteristics and dividend policy: evidence from the Warsaw Stock Exchange. Ekonomia I Prawo-Economics and Law, 18(3), 317-330. https://doi.org/10.12775/EiP.2019.022.

Pieloch-Babiarz, A. 2020. Characteristics identifying the companies conducting different dividend policy: evidence from Poland. Equilibrium Quarterly Journal of Economics and Economic Policy, 15(1), 63-85. https://doi.org/10.24136/eq.2020.004.

Rangvid. J., Schmeling, M., Schrimpf, A. 2014. Dividend predictability around the world. Journal of Financial and Quantitative Analysis, 46(6), 1255-1277. https://doi.org/10.1017/S0022109014000477.

Shao, L., Kwok, C.C.Y., Guedhami, O. 2010. Is National Culture a Missing Piece of the Dividend Puzzle. Journal of International Business Studies, 46(1), 1391-1414. https://doi.org/10.1057/jibs.2009.74.

Spence, M. 1973. Job market signaling. Quarterly Journal of Economics, 87(3), 355-374. https://doi.org/10.2307/1882010.

Tahir, M., Ibrahim, H., Zulkafli, Ab, H., Mushtaq, M. 2020. Influence of exchange rate fluctuations and credit supply on dividend repatriation policy of U.S. multinational corporations. Journal of Central Banking Theory and Practice, 9, 267-290. https://doi.org/10.2478/jcbtp-2020-0031.

Tranfield, D., Denyer, D., Smart, P. 2003. Towards a methodology for developing evidence-informed management knowledge by means of systematic review. British Journal of Management, 14(3), 207-222. https://doi.org/10.1111/1467-8551.00375.

Zipf, G.K. 1949. Human behavior and the principle of least effort: an introduction to human ecology. Addison-Wesley Press, Cambridge, 6. 